\title{
ON THE CO-ROMAN DOMINATION IN GRAPHS
}

\author{
ZeHUi SHAO \\ Institute of Computing Science and Technology \\ Guangzhou University, Guangzhou 510006, China \\ e-mail: zshao@gzhu.edu.cn
}
Seyed Mahmoud Sheikholeslami, Marzieh Soroudi
Department of Mathematics
Azarbaijan Shahid Madani University
Tabriz, I.R. Iran

e-mail: \{s.m.sheikholeslami;m.soroudi\}@@azaruniv.ac.ir

\author{
Lutz Volkmann \\ Lehrstuhl II für Mathematik \\ RWTH Aachen University 52056 Aachen, Germany \\ e-mail: volkm@math2.rwth-aachen.de \\ AND \\ Xinmiao LiU \\ Beijing Foreign Studies University \\ Beijing 100089, China
}

\begin{abstract}
Let $G=(V, E)$ be a graph and let $f: V(G) \rightarrow\{0,1,2\}$ be a function. A vertex $v$ is said to be protected with respect to $f$, if $f(v)>0$ or $f(v)=0$ and $v$ is adjacent to a vertex of positive weight. The function $f$ is a co-Roman dominating function if (i) every vertex in $V$ is protected, and (ii) each $v \in V$ with positive weight has a neighbor $u \in V$ with $f(u)=0$ such that the function $f_{u v}: V \rightarrow\{0,1,2\}$, defined by $f_{u v}(u)=1, f_{u v}(v)=f(v)-1$ and $f_{u v}(x)=f(x)$ for $x \in V \backslash\{v, u\}$, has no unprotected vertex. The weight of $f$ is $\omega(f)=\sum_{v \in V} f(v)$. The co-Roman domination number of a graph $G$, denoted by $\gamma_{c r}(G)$, is the minimum weight of a co-Roman dominating function on $G$. In this paper, we give a characterization of graphs of order $n$ for which co-Roman domination number is $\frac{2 n}{3}$ or $n-2$, which settles
\end{abstract}


two open problem in [S. Arumugam, K. Ebadi and M. Manrique, Co-Roman domination in graphs, Proc. Indian Acad. Sci. Math. Sci. 125 (2015) 1-10]. Furthermore, we present some sharp bounds on the co-Roman domination number.

Keywords: co-Roman dominating function, co-Roman domination number, Roman domination.

2010 Mathematics Subject Classification: 05C69.

\section{REFERENCES}

[1] H. Abdollahzadeh Ahangar, M.A. Henning, V. Samodivkin and I.G. Yero, Total Roman domination in graphs, Appl. Anal. Discrete Math. 10 (2016) 501-517. doi:10.2298/AADM160802017A

[2] S. Arumugam, K. Ebadi and M. Manrique, Co-Roman dominaton in graphs, Proc. Indian Acad. Sci. Math. Sci. 125 (2015) 1-10. doi:10.1007/s12044-015-0209-8

[3] R.A. Beeler, T.W. Haynes and S.T. Hedetniemi, Double Roman domination, Discrete Appl. Math. 211 (2016) 23-29. doi:10.1016/j.dam.2016.03.017

[4] E.W. Chambers, B. Kinnersley, N. Prince and D.B. West, Extremal problems for Roman domination, SIAM J. Discrete Math. 23 (2009) 1575-1586. doi:10.1137/070699688

[5] M. Chellali, T.W. Haynes, S.T. Hedetniemi and A. McRae, Roman $\{2\}$-domination, Discrete Appl. Math. 204 (2016) 22-28. doi:10.1016/j.dam.2015.11.013

[6] E.J. Cockayne, P.A. Dreyer Jr., S.M. Hedetniemi and S.T. Hedetniemi, Roman domination in graphs, Discrete Math. 278 (2004) 11-22. doi:10.1016/j.disc.2003.06.004

[7] O. Favaron, H. Karami, R. Khoeilar and S.M. Sheikholeslami, On the Roman domination number of a graph, Discrete Math. 309 (2009) 3447-3451. doi:10.1016/j.disc.2008.09.043

[8] J. Fink, M. Jacobson, L. Kinch and J. Roberts, On graphs having domination number half their order, Period. Math. Hungar. 16 (1985) 287-293. doi:10.1007/BF01848079

[9] T.W. Haynes and S.T. Hedetniemi and P.J. Slater, Fundamentals of Domination in Graphs (Marcel Dakker Inc., New York, 1998).

[10] T.W. Haynes, S.T. Hedetniemi and P.J. Slater, Domination in Graphs: Advanced Topics (Marcel Dekker Inc., New York, 1998).

[11] M.A. Henning and S.T. Hedetniemi, Defending the Roman Empire-A new strategy, Discrete Math. 266 (2003) 239-251. doi:10.1016/S0012-365X(02)00811-7 
[12] C. Payan and N.H. Xuong, Domination-balanced graphs, J. Graph Theory 6 (1982) 23-32.

doi:10.1002/jgt.3190060104

[13] C.S. ReVelle and K.E. Rosing, Defendens imperium Romanum: a classical problem in military strategy, Amer. Math. Monthly 107 (2000) 585-594. doi: $10.2307 / 2589113$

[14] I. Stewart, Defend the Roman Empire, Sci. Amer. 281 (1999) 136-138. doi:10.1038/scientificamerican1299-136

[15] Z. Zhang, Z. Shao and X. Xu, On the Roman domination numbers of generalized Petersen graphs, J. Combin. Math. Combin. Comput. 89 (2014) 311-320.

Received 21 October 2016 Revised 13 September 2017 Accepted 13 September 2017 